\title{
Assessment of malpractice claims due to spinal epidural abscess
}

\author{
J. Mason DePasse, MD, Roy Ruttiman, BS, Adam E. M. Eltorai, MS, Mark A. Palumbo, MD, and \\ Alan H. Daniels, MD
}

\author{
Division of Spine Surgery, Department of Orthopaedics, Warren Alpert Medical School of Brown University, Providence, Rhode \\ Island
}

OBJECTIVE Spinal epidural abscesses (SEAs) can be difficult to diagnose and may result in neurological compromise or even death. Delays in diagnosis or treatment may worsen the prognosis. While SEA presents a high risk for litigation, little is known about the medicolegal ramifications of this condition. An enhanced understanding of potential legal implications is important for practicing spine surgeons, emergency medicine physicians, and internists.

METHODS The VerdictSearch database, a large legal-claims database, was queried for "epidural abscess"-related legal cases. Demographic and clinical data were examined for all claims; any irrelevant cases or cases with incomplete information were excluded. The effects of age of the plaintiff, sex of the plaintiff, presence of a known infection, resulting paraplegia or quadriplegia, delay in diagnosis, and delay in treatment on the proportion of plaintiff rulings and size of payments were assessed.

RESULTS In total, 56 cases met the inclusion criteria. Of the 56 cases, $17(30.4 \%)$ were settled, $22(39.3 \%)$ resulted in a defendant ruling, and 17 (30.4\%) resulted in a plaintiff ruling. The mean award for plaintiff rulings was $\$ 5,277,468$ $\pm \$ 6,348,462$ (range $\$ 185,000-\$ 19,792,000$ ), which was significantly larger than the mean award for cases that were settled out of court, $\$ 1,914,265 \pm \$ 1,313,322$ (range $\$ 100,000-\$ 4,500,000)(p<0.05$ ). The mean age of the plaintiffs was $47.0 \pm 14.4$ years; $23(41.1 \%)$ of the plaintiffs were female and $33(58.9 \%)$ were male. The proportion of plaintiff verdicts and size of monetary awards were not affected by age or sex $(p>0.49)$. The presence of a previously known infection was also not associated with the proportion of plaintiff verdicts or indemnity payments $(p>0.29)$. In contrast, juries were more likely to rule in favor of plaintiffs who became paraplegic or quadriplegic $(p=0.03)$ compared with plaintiffs who suffered pain or isolated weakness. Monetary awards for paraplegic or quadriplegic patients were also significantly higher $(p=0.003)$. Plaintiffs were more likely to win if there was a delay in diagnosis $(p=0.04)$ or delay in treatment $(p=0.006)$, although there was no difference in monetary awards $(p>0.57)$. Internists were the most commonly sued physician (named in 13 suits [23.2\%]), followed by emergency medicine physicians (named in 8 [14.3\%]), and orthopedic surgeons (named in $3[5.4 \%]$ ).

CONCLUSIONS This investigation is the largest examination of legal claims due to spinal epidural abscess to date. The proportion of plaintiff verdicts was significantly higher in cases in which the patient became paraplegic or quadriplegic and in cases in which there was delay in diagnosis or treatment. Additionally, paralysis is linked to large sums awarded to the plaintiff. Nonsurgeon physicians, who are often responsible for initial diagnosis, were more likely to be sued than were surgeons.

https://thejns.org/doi/abs/10.3171/2016.12.SPINE16814

KEY WORDS malpractice; spinal epidural abscess; closed claims analysis; infection

$\mathrm{S}$ PINAL epidural abscess (SEA) is an infection within the epidural space that can result in neurological injury, paralysis, or death. While the condition can be managed conservatively with intravenous (IV) antibiotics in select cases, urgent surgical decompression (combined with antimicrobial therapy) is typically the treatment of choice. ${ }^{2}$ SEA often presents a diagnostic challenge, as the "classic triad" of fever, back pain, and neurological deficit is present in only $13 \%-37 \%$ of patients. ${ }^{2}$ A delayed or missed diagnosis ${ }^{2}$ may lead to poor patient outcomes and a high risk for litigation.

Although the total number of medical malpractice

ABBREVIATIONS IV = intravenous; SEA = spinal epidural abscess. 
claims (both paid and unpaid) has fallen over the past decade, ${ }^{9}$ medical negligence litigation continues to drive costs and influence physician decision making. ${ }^{6}$ A 2011 report indicated that $7.4 \%$ of all physicians had a claim annually, and by age 65 between $75 \%$ and $99 \%$ of all physicians will have contended with a malpractice claim. ${ }^{7}$ Orthopedic surgeons and neurosurgeons are among the most frequently sued specialists; $14 \%$ of orthopedists and $18 \%$ of neurosurgeons face a claim annually.

The diagnostic challenge and the high risk of disability and death in SEA compound the malpractice risk. Despite this, only one previous study has addressed the medicolegal aspects of SEA. ${ }^{5}$ The authors of this 2013 study examined 19 cases of SEA (or spinal epidural hematoma) and found that delay in surgery resulted in unfavorable verdicts. The results were limited by the details available in the database.

Understanding the risk factors for malpractice litigation in SEA is essential for spine surgeons but is even more important for clinicians responsible for the initial diagnosis (i.e., primary care and emergency medicine physicians). In this investigation, factors associated with unfavorable rulings and higher indemnity payments in SEA claims were assessed. We hypothesized that delay in diagnosis, delay in treatment, and severity of neurological injury would result in a higher proportion of plaintiff (patient) verdicts and higher indemnity payments.

\section{Methods}

The VerdictSearch (ALM Media Properties, LLC) database, a large legal-claims database with over 180,000 cases spanning from February 1988 to May 2015, was queried for the term "spinal epidural abscess." Results were filtered to the "malpractice" subcategory. Data including the age and sex of the patient, the source of infection, complications, the presence of diagnostic or treatment delay, and the medical specialty of the provider were collected. The outcome of each case was assessed and recorded as defense (physician) verdict, plaintiff (patient) verdict, or settlement. Indemnity payments were also recorded. Cases were excluded if there was missing information or if the lawsuit did not pertain to SEA.

The effects of age of the plaintiff, sex of the plaintiff, presence of a known infection, severity of neurological complication, and presence of delayed diagnosis or treatment on both the proportion of cases that were settled and the proportion of cases that resulted in rulings for the plaintiff were evaluated using chi-square testing with Microsoft Excel. Effect on the amount of indemnity payment was evaluated for all variables using Student t-tests. Statistical significance was set at $\mathrm{p}<0.05$.

\section{Results \\ Case Characteristics}

In total, 68 cases were assessed; 12 cases were excluded for missing information or irrelevance, leaving a total of 56 cases for analysis.

The mean age of the plaintiffs was $47.0 \pm 14.4$ years. Of 56 plaintiffs, $23(41.1 \%)$ were female and 33 (58.9\%) male. Fourteen patients $(25 \%)$ had a known source of infection, $8(14.3 \%)$ had a recent history of epidural injection, $4(7.1 \%)$ had a known history of IV drug abuse, and 25 (44.6\%) had no known history of infection or known source of infection prior to diagnosis (Table 1).

The severity of illness ranged from permanent neurological injury (including weakness or numbness) in 23 cases $(41.1 \%$ ), to paralysis (including paraplegia or quadriplegia) in $31(55.4 \%)$, and death in $2(3.6 \%)$. A delay in diagnosis was alleged in 41 cases (73.2\%), and a delay in treatment was alleged in $9(16.1 \%)$. Physicians of multiple different specialties were named in lawsuits, including internists in 13 suits (23.2\%), emergency medicine physicians in $8(14.3 \%)$, anesthesia in $6(10.7 \%)$, family practitioners in 4 (7.1\%), and orthopedic surgeons in 3 (5.4\%) (Table 1).

\section{Case Outcomes}

Of the 56 cases, 17 (30.4\%) were settled and 39 (69.6\%) went to trial. Of those that proceeded to trial, 22 (56.4\%) resulted in a defendant ruling and 17 (43.6\%) resulted in a plaintiff ruling. Overall, $30.4 \%$ of all cases resulted in a verdict for the plaintiff.

The mean award for plaintiff rulings was $\$ 5,277,468$ $\pm \$ 6,348,462$ (range $\$ 185,000-\$ 19,792,000$, median $\$ 2,500,000$ ), which was significantly larger than the mean award for cases that were settled out of court, $\$ 1,914,265$ $\pm \$ 1,313,322$ (range $\$ 100,000-\$ 4,500,000$, median $\$ 2,200,000)(\mathrm{p}<0.05)$.

\section{Demographic Factors}

In the 31 cases (55.4\%) in which the plaintiff was under 50 years of age, there was no difference in either the proportion of settlements versus court cases or the proportion of plaintiff versus defendant verdicts when compared with cases in which the plaintiff was over $50(\mathrm{p}>0.49)$. Similarly, for the 33 cases $(58.9 \%)$ with male plaintiffs, there was no difference in either proportion when compared with cases with female plaintiffs $(p>0.56)$. Neither age nor sex were significantly related to the size of the indemnity payments $(\mathrm{p}>0.62)$.

\section{Source of Infection}

In 14 cases (25\%), the plaintiff had a known source of infection prior to diagnosis of SEA, such as remote Staphylococcus skin infection, pneumonia, or known bacteremia. When compared with the 25 cases $(44.6 \%)$ with no known infection or other risk factors, there was no difference in proportion of settlements, proportion of plaintiff verdicts, or indemnity payments $(\mathrm{p}>0.29)$.

\section{Neurological Sequelae}

Thirty-one plaintiffs $(55.4 \%)$ suffered complete paraplegia or quadriplegia as a result of SEA, while $23(41.1 \%)$ complained of less severe permanent neurological injury, such as leg or arm weakness, numbness, or difficulty ambulating. Paralysis was clearly noted preoperatively in 30 of the 31 cases of paraplegia or quadriplegia, and severe weakness was noted preoperatively in the remaining case. Although there was no difference in the proportion of 
TABLE 1. SEA suit case characteristics

\begin{tabular}{|c|c|}
\hline Variable & Value \\
\hline Mean age in yrs & $47.0 \pm 14.4$ \\
\hline \multicolumn{2}{|l|}{ Sex } \\
\hline Female & $23(41.1 \%)$ \\
\hline Male & $33(58.9 \%)$ \\
\hline \multicolumn{2}{|l|}{ Mechanism } \\
\hline Known infection & 14 \\
\hline Unknown infection & 25 \\
\hline Spinal injection & 8 \\
\hline IV drug use & 4 \\
\hline Other & 5 \\
\hline \multicolumn{2}{|l|}{ Complication } \\
\hline Paralysis & 31 \\
\hline Weakness & 23 \\
\hline Death & 2 \\
\hline Delay in diagnosis & $41(73.2 \%)$ \\
\hline Delay in treatment & $9(16.1 \%)$ \\
\hline \multicolumn{2}{|l|}{ Profession sued } \\
\hline Internist & 13 \\
\hline Hospital & 11 \\
\hline Emergency medicine & 8 \\
\hline Anesthesia & 6 \\
\hline Family medicine & 4 \\
\hline Orthopedics & 3 \\
\hline Other & 12 \\
\hline
\end{tabular}

Values are numbers of cases unless otherwise indicated.

settlements in cases with paralyzed plaintiffs $(p=0.18)$, paralyzed plaintiffs were more likely to receive a plaintiff verdict ( $\mathrm{p}=0.03$ ) (Table 2). Furthermore, the mean award for paralyzed plaintiffs was $\$ 4,699,772 \pm \$ 5,369,684$, which was significantly larger $(p=0.003)$ than for plaintiffs without devastating neurological sequelae, $\$ 946,491$ $\pm \$ 815,137$.

\section{Delay in Diagnosis or Treatment}

In 41 cases $(73.2 \%)$, there was an alleged delay in diagnosis. Compared with cases in which there was no delay, cases with a delayed diagnosis were both more likely to be settled $(p=0.02)$ or result in a plaintiff verdict if the case went to court $(p=0.04)$ (Table 3). Similarly, in the 9 cases $(16.1 \%)$ in which there was alleged delay in treat-

TABLE 2. Outcomes for paralyzed plaintiffs and plaintiffs with weakness

\begin{tabular}{ccc}
\hline \multicolumn{1}{c}{ Outcome } & Paralysis & Weakness \\
\hline Settlement & 12 & 5 \\
\hline Court case & 19 & 18 \\
\hline Plaintiff verdict & $12^{*}$ & 5 \\
\hline Defense verdict & 7 & 13 \\
\hline
\end{tabular}

* Statistically significant difference $(p<0.05)$.
TABLE 3. Outcomes for cases with and without delayed diagnosis

\begin{tabular}{lcc}
\hline \multicolumn{1}{c}{ Outcome } & Delay in Diagnosis & No Delay \\
\hline Settlement & $16^{*}$ & 1 \\
\hline Court case & 25 & 14 \\
\hline Plaintiff verdict & $14^{*}$ & 3 \\
\hline Defense verdict & 11 & 11 \\
\hline
\end{tabular}

* Statistically significant difference $(p<0.05)$.

ment after the diagnosis of SEA had been made, plaintiffs were more likely to win $(p=0.006)$ (Table 4$)$. In this small series, there were no cases with a physician verdict when there was an alleged delay in treatment and the case went to trial. However, delay in treatment did not affect the proportion of cases that were settled $(p=0.32)$. Neither delay in diagnosis nor delay in treatment lead to increased monetary awards ( $\mathrm{p}>0.57)$.

\section{Discussion}

SEA is a medical emergency that not only can be difficult to diagnose but requires prompt diagnosis and treatment to prevent or limit severe neurological injury. ${ }^{2}$ As such, SEA presents a high risk for malpractice litigation. ${ }^{7}$ Previous closed claims analyses have evaluated spine surgical claims ${ }^{8,12,13}$ and claims after cauda equina syndrome, ${ }^{1}$ but only 1 small study of 19 cases, including only 4 plaintiff verdicts, has investigated the medicolegal impacts of SEA. ${ }^{5}$ In the present study we used a more extensive and validated database to assess more factors over a much larger sample size. Our findings indicate that paralysis, delayed diagnosis, and delayed treatment all result in more plaintiff wins, while plaintiff age, sex, and preexisting infection did not affect case outcomes.

It is not surprising that age and sex were not associated with plaintiff verdicts or monetary awards. This finding is consistent with the previous SEA study by French et al. ${ }^{5}$ as well as the cauda equina study by Daniels et al. ${ }^{1}$ Although a study by Oetgen and Parikh ${ }^{10}$ found that the percentage of general orthopedic malpractice claims resulting in payment was higher for pediatric patients, there were no juvenile plaintiffs in this study. The youngest plaintiff age was 23 years.

Though the presence of a known infectious source may raise suspicion for SEA and thus assist physicians with an earlier diagnosis, there was no association between known infection prior to diagnosis and case outcomes. In this

TABLE 4. Outcomes for cases with and without delayed treatment

\begin{tabular}{lcc}
\hline \multicolumn{1}{c}{ Outcome } & Delay in Treatment & No Delay \\
\hline Settlement & 4 & 13 \\
\hline Court case & 5 & 34 \\
\hline Plaintiff verdict & $5^{\star *}$ & 12 \\
\hline Defense verdict & 0 & 22 \\
\hline
\end{tabular}

** Highly significant difference $(p<0.01)$. 
study, known infections included skin infections as well as internal infections, which were represented by conditions such as pneumonia, appendicitis, bacteremia, and discitis. It is likely that the lack of association with outcome is due to the individualized effects of known infections. Some known infections assisted physicians with prompt diagnosis, and some were used by plaintiffs to argue that SEA should have been diagnosed earlier. Ultimately, the critical issue is whether diagnostic delay was present.

Although French et al. ${ }^{5}$ did not note any association between complication and case outcome, it is likely that sample size was a limiting factor. Two of the 4 winning plaintiffs in their study had suffered paraplegia. In our study, paralyzed plaintiffs were more likely to both win verdicts and receive higher monetary awards. Juries are likely more sympathetic to paralyzed plaintiffs. Our sample included only 4 quadriplegic patients, so we were unable to assess whether there are further differences between quadriplegic and paraplegic plaintiffs.

Both alleged delay in diagnosis and delay in treatment resulted in more plaintiff rulings, although neither affected monetary awards. Delayed diagnosis was alleged when plaintiffs argued that a competent physician should have performed an appropriate workup for SEA, including advanced radiological imaging, at an earlier time point. Delay in treatment was alleged when plaintiffs argued that surgery was delayed despite a known diagnosis of SEA. Since either form of delay can significantly worsen outcome, it is logical that these delays were associated with plaintiff verdicts. This is consistent with the study by French et al., in which the mean time to surgery in cases with plaintiff rulings was 33 days, compared with 19 days in cases with defendant rulings. ${ }^{5}$ The authors concluded that time to surgery was the only significant factor associated with case outcomes, though both of these times to surgery are surprisingly long.

In the current study, no case with an alleged delay in treatment that went to trial resulted in a ruling for the defendant. While delay in diagnosis was commonly alleged, some juries found that no physician would have reasonably suspected SEA or that no delay in diagnosis had occurred. However, delay in treatment is easier to measure. Once the diagnosis is known, physicians should promptly initiate treatment and obtain surgical consultation to avoid suboptimal outcomes and malpractice litigation.

It is important for physicians to recognize which professions are sued after SEA. Most commonly, it is not the surgeon but the clinician responsible for making the initial diagnosis (i.e., internists, primary care physicians, and emergency medicine physicians).

Our study had several potential limitations. VerdictSearch, although large, is not a comprehensive database. Cases are selected by case attorneys and published to the website after review by the VerdictSearch staff and input from both plaintiff and defense counsel. Thus, the cases available for review could be affected by selection bias. As the database is national, case outcomes may be affected by regional or state laws, but we were unable to evaluate for regional effects due to limited power. Additionally, the database is not created for health care professionals. The variability in medical detail limits assessment of factors such as affected spinal levels and specific time to surgery. Still, VerdictSearch has been used in several previous studies to evaluate closed claims. ${ }^{3,4,11}$

This investigation represents the largest study to date on SEA malpractice suits and provides valuable information for clinicians in multiple specialties. Specifically, surgeons should never delay or defer treatment of a diagnosed SEA, and surgeons should always insist on prompt advanced imaging in cases in which SEA is suspected, although the consulting provider is most often the clinician at risk for malpractice litigation. Further, surgeons should note that paraplegic or quadriplegic patients are more likely to win in court, even if the paralysis is noted preoperatively, and thus especially thorough documentation is important when treating a paralyzed patient. Additional research will provide further insight into whether these factors apply to other orthopedic and spinal emergencies.

\section{References}

1. Daniels EW, Gordon Z, French K, Ahn UM, Ahn NU: Review of medicolegal cases for cauda equina syndrome: what factors lead to an adverse outcome for the provider? Orthopedics 35:e414-e419, 2012

2. DeFroda SF, DePasse JM, Eltorai AEM, Daniels AH, Palumbo MA: Evaluation and management of spinal epidural abscess. J Hosp Med 11:130-135, 2016

3. Epstein NE: It is easier to confuse a jury than convince a judge: the crisis in medical malpractice. Spine (Phila Pa 1976) 27:2425-2430, 2002

4. Epstein NE: A review of medicolegal malpractice suits involving cervical spine: what can we learn or change? J Spinal Disord Tech 24:15-19, 2011

5. French KL, Daniels EW, Ahn UM, Ahn NU: Medicolegal cases for spinal epidural hematoma and spinal epidural abscess. Orthopedics 36:48-53, 2013

6. Jena AB, Schoemaker L, Bhattacharya J, Seabury SA: Physician spending and subsequent risk of malpractice claims: observational study. BMJ 351:h5516, 2015

7. Jena AB, Seabury S, Lakdawalla D, Chandra A: Malpractice risk according to physician specialty. N Engl J Med 365:629-636, 2011

8. Matsen FA III, Stephens L, Jette JL, Warme WJ, Posner KL: Lessons regarding the safety of orthopaedic patient care: an analysis of four hundred and sixty-four closed malpractice claims. J Bone Joint Surg Am 95:e201-e208, 2013

9. Mello MM, Studdert DM, Kachalia A: The medical liability climate and prospects for reform. JAMA 312:2146-2155, 2014

10. Oetgen ME, Parikh PD: Characteristics of orthopaedic malpractice claims of pediatric and adult patients in private practice. J Pediatr Orthop 36:213-217, 2016

11. Quigley RS, Akpolat YT, Forrest BD, Wongworawat MD, Cheng WK: Reason for lawsuit in spinal cord injury affects final outcome. Spine (Phila Pa 1976) 40:851-855, 2015

12. Rovit RL, Simon AS, Drew J, Murali R, Robb J: Neurosurgical experience with malpractice litigation: an analysis of closed claims against neurosurgeons in New York State, 1999 through 2003. J Neurosurg 106:1108-1114, 2007

13. Steele L, Mukherjee S, Stratton-Powell A, Anderson I, Timothy J: Extent of medicolegal burden in neurosurgery-an analysis of the National Health Service Litigation Authority Database. Br J Neurosurg 29:622-629, 2015

\section{Disclosures}

Dr. Palumbo reports a consultant relationship with Stryker Spine. 
Dr. Daniels reports consultant relationships with Stryker, Orthofix, DePuy, and Globus.

\section{Author Contributions}

Conception and design: Daniels, DePasse, Palumbo. Acquisition of data: DePasse, Ruttiman, Eltorai. Analysis and interpretation of data: DePasse, Ruttiman, Eltorai. Drafting the article:

DePasse. Critically revising the article: Daniels, DePasse, Eltorai, Palumbo. Reviewed submitted version of manuscript: Daniels,
DePasse, Palumbo. Approved the final version of the manuscript on behalf of all authors: Daniels. Statistical analysis: DePasse. Administrative/technical/material support: Palumbo.

\section{Correspondence}

Alan H. Daniels, Department of Orthopaedics, Warren Alpert Medical School of Brown University, 100 Butler Dr., Providence, RI 02906. email: alandanielsmd@gmail.com. 